\title{
Common mental disorders and association with telomere length (Review)
}

\author{
E. VAKONAKI ${ }^{1 *}$, K. TSIMINIKAKI $^{1 *}$, S. PLAITIS $^{1}$, P. FRAGKIADAKI ${ }^{1}$, D. TSOUKALAS ${ }^{1}$, I. KATSIKANTAMI $^{1}$, \\ G. VAKI ${ }^{1}$, M.N. TZATZARAKIS ${ }^{1}$, D.A. SPANDIDOS ${ }^{2}$ and A.M. TSATSAKIS ${ }^{1}$ \\ ${ }^{1}$ Laboratory of Toxicology Science and Research, Medical School, University of Crete, 71003 Heraklion; \\ ${ }^{2}$ Laboratory of Clinical Virology, Medical School, University of Crete, 71409 Heraklion, Crete, Greece
}

Received December 7, 2017; Accepted January 8, 2018

DOI: $10.3892 /$ br.2018.1040

\begin{abstract}
Telomeres are repeated 5'-TTAGGG-3' sequences at the end of chromosomes, which maintain genomic stability. Their length is related to a number of diseases that affect humans. Apart from cancer, cardiovascular diseases, diabetes and other, telomere length has been associated with chronic diseases. Chronic mental illness includes various types of mental disorders with the most common being depression, schizophrenia and stress-anxiety. The aim of this review is to summarize the current state of knowledge on the role of telomeres in these disorders and to compare telomere length variations in patients receiving medication and patients not taking treatment. Most studies report reduced telomere length in patients suffering from mental disorders, compared to the general population. Since the factors that can affect telomere length are various, more experiments and investigations are required to understand the general impact of different factors on telomere length.
\end{abstract}

\section{Contents}

1. Introduction

2. Depression

3. Schizophrenia

4. Stress-anxiety

5. Discussion

\section{Introduction}

Telomeres are chromatin structures at the end of chromosomes, composed of tandem repeats of the sequence 5'-TTAGGG-3',

Correspondence to: Professor Aristides M. Tsatsakis, Laboratory of Toxicology Science and Research, Medical School, University of Crete, 71003 Heraklion, Crete, Greece

E-mail: tsatsaka@uoc.gr

*Contributed equally

Key words: telomeres, depression, schizophrenia, stress-anxiety and protect chromosomes from degradation and recombination (1). Telomeres are also coated with a protein complex, which consists of a group of proteins: telomere repeat-binding factor 1 (TRF1) and 2 (TRF2), which interact with nuclear protein 2 (TIN2); repressor activator protein 1 (Rap1); tripeptidyl-peptidase 1 (TPP1); and protection of telomere 1 (POT1), and are also known as shelterin proteins $(2,3)$. These are packed into a compact T-loop structure to prevent the DNA repair machinery from recognizing and processing telomeres during the repairing double-stranded DNA breaks (3).

Telomere length decreases with each cell division due to incomplete replication of linear chromosomes. High proliferating cells produce telomerase, an enzyme that acts as a reverse-transcriptase, and is responsible for catalyzing the addition of nucleotides using an RNA template. However, telomerase activity is not sufficient to prevent telomere shortening $(4,5)$. When telomere length becomes critically short, proliferation is arrested, and the risk of apoptosis is increased (6-8). Therefore, telomeres and telomerase activity have been characterized as biomarkers of cellular aging $(9,10)$.

A growing number of studies have linked shorter telomeres to health behaviors, such as smoking, and aging and age-related diseases including cancer, coronary heart (cardiovascular) disease, and diabetes (11-16). In addition, previous findings have shown a correlation between telomere length and depression, stress, schizophrenia, drug abuse and Alzheimer disease (17-21).

The aim of this review is to indicate the association between telomere length and mental illnesses such as depression and schizophrenia, and evaluate the potency of telomere length as biomarker of early aging.

\section{Depression}

Depression is not only a brain disorder, but a condition affecting the whole body (22). This is due to the fact that increased psychological and chronic stress has been associated with accelerated aging, telomere length shortening and the psychopathological characteristics of major depressive disorders (23-25).

In addition, the complex mechanisms of hypothalamic pituitary adrenal axis, brain-derived neurotrophic factor, oxidative 
or inflammatory stress, excitotoxicity, neurosteroids, mitochondrial DNA, leukocyte telomere length and telomerase are biochemical mediators of cell dysfunction or damage and have been linked to major depressive disorder $(26,27)$. Moreover, symptoms of depression are related to oxidative stress and inflammation $(22)$. They reduce telomerase activity $(22,28)$ and decrease levels of neurotrophic factors $(29,30)$, but increase apoptosis $(6,7)$ and reduce stem cell proliferation (31).

Depression is partly heritable and the severe and early-onset forms of depression may have a higher heritability than other forms of depression (32). Over the last few decades, several studies have identified an association between bipolar disorders and diseases that cause accelerated aging, including cardiovascular diseases (33). Thus, it has been hypothesized that depression symptoms may lead to accelerated aging by decreasing telomere length $(22,34)$.

Simon et al investigated the relationship between mood disorders and telomere length and found that telomeres were significantly shorter in patients with mood disorders overall, and in patients with major depressive disorders (34). This finding was confirmed by Wolkowitz et al who reported that the biological age of patients with depression was 10 years older compared to their chronological age (22). The mechanism of aging caused by depression includes increased rates of reactive oxygen species (ROS) and reactive nitrogen species (RNS), which result in unspecific damage of intracellular compartments including cell membranes, organelles, DNA and telomeres $(35,36)$. In a more recent study, Verhoeven et al demonstrated that individuals with major depression had shorter telomeres compared to the control group, and that severity and duration of the disorder were inversely correlated to telomere length (37). In that study, no association between psychotropic medication use and telomere length was reported (37). In this regard, Elvsåshagen et al observed no differences in telomere length of patients with or without use of medicines for depression (38). One year later, Needham et al came to contradict the results by Verhoeven et al (37) with his experiment where young adults, who suffered from severe depression and used antidepressants, had statistically significant shorter telomere length than those who were not under treatment (39).

Lung et al and Philips et al have shown shorter telomeres in depressive patients populations, but the levels of decrease changed with age $(40,41)$. Telomere length was higher in the youngest group, depending on the duration of the disorder and the severity of symptoms, while men and women with depression (using or not antidepressants) had similar lengths (40). This similarity between men and women was also confirmed by Wikgren et al (42), who observed significant shorter telomere length in patients with depression, and by Hartmann et al (43) who also found notably shorter telomeres compared to the control group, as the dose of antidepressants increased (independent from duration and severity of disease).

In addition, severe depressive symptomatology, as indicated by being medically treated either in a clinical setting or by psychotropic medication, has been associated with shorter telomere length even in early adulthood, as described by Needham et al (39). However, less severe forms of psychopathology were not correlated with telomere length.

In the studies of Wolkowitz et al, Simon et al, Wikgren et al and Hartmann et al, it was shown that telomere shortening occurred only in patients with a long lasting (10-30 years) depression disorder $(22,34,42,43)$. Thus, the increased load of short telomeres in the patient group may represent 13 years of accelerated aging. Similarly, the reduction in mean telomere length among patients is equivalent to 11 years of accelerated aging (38).

It is worth mentioning that mixed results in depression and telomere studies may be due in part to the presence of potentially uncontrolled confounding factors such as variably assessed medical illness and life stressors; however, not all studies with positive results failed to control for multiple confounding variables (44). Thus, the lifetime of the illness cannot explain the prognosis of major depressive disorders, due to heterogeneity of treatment response and self-resilience against the stress, both factors of leukocyte telomere length shortening (45).

\section{Schizophrenia}

Schizophrenia is a complex neurodevelopmental disorder characterized by mental dysfunction in multiple domains of the brain (46). Previous studies have shown lower telomere length in patients with schizophrenia and paranoid schizophrenia compared to control groups $(47,48)$. Patients suffering from paranoid schizophrenia, who were under anti-psychotics medication had slightly decreased leukocyte telomere length. In addition, telomere length analysis of paranoid schizophrenic patients revealed that response to treatment influences telomere length with poor responders having the shorter telomeres (49). By contrast, other authors have shown that the poor responders had the shortest terminal restriction fragments (TRFs) which was inversely associated with age. Furthermore, Fernandez-Egea et al (19), who included both men and women, showed that the whole psychosis group had decreased telomere content compared to the control group and that both men and women had the same telomere content. However, when patients and controls were analyzed separately men showed a higher extent of telomere length shortening than women that was affected by age (50).

At this point, it is important to mention that both typical and atypical antipsychotics affect leucocyte functioning $(51,52)$. In particular, according to Leykin et al (51), clozapine and haloperidol inhibited in vitro leukocyte mitosis stimulation by phytohemagglutinin in $50 \%$ of treated patients, and suppressed the production of the interleukins analyzed. Accordingly, in vitro experiments using clozapine and haloperidol separately and above the therapeutic dosage, resulted in decreased telomerase expression in leukocytes of healthy individuals' (53). Furthermore, Rao et al (54) showed that leukocyte telomere length was markedly shortened in patients with schizophrenia who presented poor response to antipsychotics. Although the exact mechanism remains to be unraveled, these findings are most probably linked to high levels of oxidative stress.

In contrast to the above, Savolainen et al concluded that patients who were under medication had longer telomere length than healthy subjects and two possible mechanisms might be involved (55). Firstly, antipsychotics can function in a way that prevents oxidative stress and its effects, protecting telomeres from erosion and leading to longer telomeres. Secondly, psychotropic medications are correlated with the 
Wnt/ $\beta$-catenin pathway, which increases telomerase expression by activating TCF4 $(56,57)$. However, these results need to be interpreted with caution, because the study population included mixed patients suffering from severe mental or substance abuse disorder, hospitalized at some point from 1969 onwards. Thus, the health state of these patients was not assessed at the time of the study and bias of survival cannot be excluded. In addition, baseline telomere length measurements were not included, probable administration of polypharmacy treatment, having protective effect on telomere, and methodology limitations may explain these findings.

Schizophrenia is a brain disorder linked to several genetic and environmental factors that play an important role in the development of the disorder (58). This was one of the reasons which led to the characterization of schizophrenia as a syndrome of accelerated aging (59-61). Nevertheless, it is worth mentioning that the disorder itself and its development are associated with increased physiological changes in the organism, which are correlated with normal aging. Such changes include hyperlipidemia, decreased bone density, insulin resistance, cortical atrophy, thinning and wrinkling of the skin and hair, increased blood pressure and decrease in muscle mass (61). In addition, oxidative stress is one of the factors of telomere shortening and given the fact that oxidative stress is really high in this type of schizophrenia, this could increase telomere erosion as demonstrated in some reports of schizophrenic patients with shorter telomers $(62,63)$.

It has been previously shown that oxidative stress can cause mitochondrial dysfunction and altered brain metabolism in schizophrenia, suggesting that increased oxidative stress may exist in poor responders with chronic schizophrenia (64). This is supported by a study showing that oxidative DNA damage was 10 -fold higher in post-mortem hippocampi of elderly patients with 'poor-outcome' schizophrenia (65). Thus, it becomes apparent that oxidative stress plays a major role in this disorder, and the possible cause of oxidative stress in schizophrenia may be the reduction in antioxidant capacity and elevated levels of oxygen-free radicals (66-68).

However, further studies are needed to establish the status and the role of oxidative stress in the pathogenesis of schizophrenia, in good and poor responders with chronic schizophrenia, and to evaluate the association of telomere length with this disorder. Of note, the effect of psychiatric medication on telomere shortening should be considered with caution, since all antipsychotics act in the central nervous system and most studies measured telomere length in leukocytes DNA.

\section{Stress-anxiety}

Psychological stress is commonly observed in modern society and a high percentage of individuals suffer from high levels of anxiety. Early or recent in life, chronic exposure to psychosocial stressors, has been associated with numerous diseases including obesity and abnormal fat deposition, metabolic syndrome, cardiovascular disease, systemic inflammation, and dendritic shortening in the hippocampus and prefrontal cortex (69). Chronic stress can lead to overeating, co-elevation of cortisol and insulin, suppression of certain anabolic hormones and this can promote systemic inflammation and oxidative stress (69).

The abovementioned biochemical environment, leads to telomere length shortening and cell senescence. Previous studies have shown that telomeric DNA can be damaged by oxidative stress $(70,71)$. Leukocyte telomere length is a well-studied indicator of cellular aging and it is influenced by age, sex, health behaviors such as smoking (72), genetic predisposition (73) and psychosocial factors, including mental health (74). Verhoeven et al suggest that anxiety disrupts the hypothalamic-pituitary axis and immune function, and increases oxidative stress, leading to telomere damaging (75). A number of studies have examined the relationship between anxiety, chronic stress and telomere length. Hoen et al found a significant association between high anxiety levels and telomere shortening (76). The results from a meta-analysis study by Malouff and Schutte showed a weak but significant association between high anxiety and shorter telomeres in 19,424 participants. Those authors suggest that anxiety may lead to shorter telomeres which could lead to a shorter lifespan (77). In line with these findings, Mathur et al (78), who examined the association between perceived stress and telomere length found a weak but statistically significant relationship between increased psychological stress and decreased telomere length, but they suggest that this association may be stronger with known major stressors. Malouff and Schutte also supported that according to the literature, long-term chronic stress may have a larger cumulative effect (77).

In addition, Wang et al studied the differences in telomere length between primary health care patients with anxiety or stress, and they observed that telomere length was significantly shorter in patients compared to the controls. They also examined the association between telomere length and baseline characteristics in these patients and they observed shorter telomere length in male, overweighed, and elderly participants. Finally, they examined the potential effects of the 8-week treatments with a mindfulness-based therapy on telomere length and they demonstrated that telomere length remained unchanged (79).

Taken together, it can be assumed that individuals with an anxiety disorder or perceived stress might be at greater risk of telomere shortening. However, future intervention studies on the impact of antidepressant treatment on telomere length are to further clarify the role of anxiety on telomere length changes.

\section{Discussion}

The majority of the studies included in the present review have identified increased telomere erosion in patients suffering from one of the aforementioned disorders (schizophrenia, depression, stress-anxiety).

Schizophrenia, depression and stress-anxiety are closely related. In fact, patients with chronic symptoms of schizophrenia, experience intense stress because of the disorder and have decreased telomere length due to the combination of the two conditions (54). The same effect has been observed in the case of depression and stress. Phillips et al found that the effects of depressive symptoms on telomere length are 
limited, and can only be detected in younger groups in which the impact of the individual's age on telomere length decrease is less strong (41). These findings oppose the concept that the effects of stress are expected to increase and accumulate in older ages. Based on this, it is expected that the effects of the disease are stronger in older ages, because early age of illness seems to have contrary effects on prognosis. Therefore, it is necessary to define a certain time interval before evaluating the effects of any disease on telomere length and biological age, in order to have relevant results including any factor that may influence these results.

However, there are some limitations in most studies. Variables including sex, age, BMI, the individual's lifestyle and health condition, should be considered to produce statistically significant results. Finally, other morbidities (such as cancer, diabetes and cardiovascular disease, unaware medical illness) might confound differences in leukocyte telomere length between cases and controls (80-82).

To conclude, more experiments and investigations should be carried out to understand the general impact of different factors on telomere length.

\section{Competing interests}

D.A. Spandidos is the Editor-in-Chief for the journal, but had no personal involvement in the reviewing process, or any influence in terms of adjudicating on the final decision, for this article.

\section{References}

1. Aubert G and Lansdorp PM: Telomeres and aging. Physiol Rev 88: 557-579, 2008.

2. Swanson MJ, Baribault ME, Israel JN and Bae NS: Telomere protein RAP1 levels are affected by cellular aging and oxidative stress. Biomed Rep 5: 181-187, 2016.

3. de Lange T: Shelterin: The protein complex that shapes and safeguards human telomeres. Genes Dev 19: 2100-2110, 2005.

4. Collins K and Mitchell JR: Telomerase in the human organism. Oncogene 21: 564-579, 2002.

5. Harley CB, Futcher AB and Greider CW: Telomeres shorten during ageing of human fibroblasts. Nature 345: 458-460, 1990.

6. Blasco MA: Telomere length, stem cells and aging. Nat Chem Biol 3: 640-649, 2007.

7. Hemann MT, Strong MA, Hao LY and Greider CW: The shortest telomere, not average telomere length, is critical for cell viability and chromosome stability. Cell 107: 67-77, 2001.

8. Samper E, Flores JM and Blasco MA: Restoration of telomerase activity rescues chromosomal instability and premature aging in $\mathrm{Terc}^{-/}$mice with short telomeres. EMBO Rep 2: 800-807, 2001.

9. Blasco MA: Telomeres and human disease: Ageing, cancer and beyond. Nat Rev Genet 6: 611-622, 2005.

10. Collado M, Blasco MA and Serrano M: Cellular senescence in cancer and aging. Cell 130: 223-233, 2007.

11. Willeit P, Willeit J, Brandstätter A, Ehrlenbach S, Mayr A, Gasperi A, Weger S, Oberhollenzer F, Reindl M, Kronenberg F and Kiechl S: Cellular aging reflected by leukocyte telomere length predicts advanced atherosclerosis and cardiovascular disease risk. Arterioscler Thromb Vasc Biol 30: 1649-1656, 2010.

12. Aviv A: Telomeres and human aging: Facts and fibs. Sci Aging Knowledge Environ 2004, pe43, 2004.

13. Demissie S, Levy D, Benjamin EJ, Cupples LA, Gardner JP, Herbert A, Kimura M, Larson MG, Meigs JB, Keaney JF and Aviv A: Insulin resistance, oxidative stress, hypertension, and leukocyte telomere length in men from the Framingham Heart Study. Aging Cell 5: 325-330, 2006.
14. Fitzpatrick AL, Kronmal RA, Gardner JP, Psaty BM, Jenny NS, Tracy RP, Walston J, Kimura M and Aviv A: Leukocyte telomere length and cardiovascular disease in the cardiovascular health study. Am J Epidemiol 165: 14-21, 2007.

15. Astrup AS, Tarnow L, Jorsal A, Lajer M, Nzietchueng R, Benetos A, Rossing P and Parving HH: Telomere length predicts all-cause mortality in patients with type 1 diabetes. Diabetologia 53: 45-48, 2010.

16. Olivieri F, Lorenzi M, Antonicelli R, Testa R, Sirolla C, Cardelli M, Mariotti S, Marchegiani F, Marra M, Spazzafumo L, et al: Leukocyte telomere shortening in elderly Type2DM patients with previous myocardial infarction. Atherosclerosis 206: 588-593, 2009.

17. Karabatsiakis A, Kolassa IT, Kolassa S, Rudolph KL and Dietrich DE: Telomere shortening in leukocyte subpopulations in depression. BMC Psychiatry 14: 192, 2014.

18. Ladwig KH, Brockhaus AC, Baumert J, Lukaschek K, Emeny RT, Kruse J, Codd V, Häfner S, Albrecht E, Illig T, et al: Posttraumatic stress disorder and not depression is associated with shorter leukocyte telomere length: Findings from 3,000 participants in the population-based KORA F4 study. PLoS One 8: e64762, 2013.

19. Fernandez-Egea E, Bernardo M, Heaphy CM, Griffith JK, Parellada E, Esmatjes E, Conget I, Nguyen L, George V, Stöppler H and Kirkpatrick B: Telomere length and pulse pressure in newly diagnosed, antipsychotic-naive patients with nonaffective psychosis. Schizophr Bull 35: 437-442, 2009.

20. Yang Z, Ye J, Li C, Zhou D, Shen Q, Wu J, Cao L, Wang T, Cui D, He S, et al: Drug addiction is associated with leukocyte telomere length. Sci Rep 3: 1542, 2013.

21. Thomas P, O' Callaghan NJ and Fenech M: Telomere length in white blood cells, buccal cells and brain tissue and its variation with ageing and Alzheimer's disease. Mech Ageing Dev 129: 183-190, 2008.

22. Wolkowitz OM, Epel ES, Reus VI and Mellon SH: Depression gets old fast: Do stress and depression accelerate cell aging? Depress Anxiety 27: 327-338, 2010.

23. Hammen C: Stress and depression. Annu Rev Clin Psychol 1: 293-319, 2005

24. Alloy LB, Liu RT and Bender RE: Stress generation research in depression: A commentary. Int J Cogn Ther 3: 380-388, 2010.

25. McEwen BS; McEwenBS: Mood disorders and allostatic load. Biol Psychiatry 54: 200-207, 2003.

26. Kapczinski F, Dal-Pizzol F, Teixeira AL, Magalhaes PV, Kauer-Sant'Anna M, Klamt F, Moreira JC, de Bittencourt Pasquali MA, Fries GR, Quevedo J, et al: Peripheral biomarkers and illness activity in bipolar disorder. J Psychiatr Res 45: 156-161, 2011.

27. Kinser PA and Lyon DE: Major depressive disorder and measures of cellular aging: An integrative review. Nurs Res Pract 2013: 469070, 2013.

28. Epel ES, Blackburn EH, Lin J, Dhabhar FS, Adler NE, Morrow JD and Cawthon RM: Accelerated telomere shortening in response to life stress. Proc Natl Acad Sci USA 101: 17312-17315, 2004.

29. Berk M, Kapczinski F, Andreazza AC, Dean OM, Giorlando F, Maes M, Yücel M, Gama CS, Dodd S, Dean B, et al: Pathways underlying neuroprogression in bipolar disorder: Focus on inflammation, oxidative stress and neurotrophic factors. Neurosci Biobehav Rev 35: 804-817, 2011.

30. Monteleone P, Serritella C, Martiadis V and Maj M: Decreased levels of serum brain-derived neurotrophic factor in both depressed and euthymic patients with unipolar depression and in euthymic patients with bipolar I and II disorders. Bipolar Disord 10: 95-100, 2008.

31. Ferrón SR, Marqués-Torrejón MA, Mira H, Flores I, Taylor K, Blasco MA and Fariñas I: Telomere shortening in neural stem cells disrupts neuronal differentiation and neuritogenesis. J Neurosci 29: 14394-14407, 2009.

32. Kendler KS, Karkowski LM and Prescott CA: Fears and phobias: Reliability and heritability. Psychol Med 29: 539-553, 1999.

33. Fyhrquist F and Saijonmaa O: Telomere length and cardiovascular aging. Ann Med 44 (Suppl 1): 138-142, 2012.

34. Simon NM, Smoller JW, McNamara KL, Maser RS, Zalta AK, Pollack MH, Nierenberg AA, Fava M and Wong KK: Telomere shortening and mood disorders: Preliminary support for a chronic stress model of accelerated aging. Biol Psychiatry 60: 432-435, 2006. 
35. Brieger K, Schiavone S, Miller FJ Jr and Krause KH: Reactive oxygen species: From health to disease. Swiss Med Wkly 142: w13659, 2012.

36. von Zglinicki T: Oxidative stress shortens telomeres. Trends Biochem Sci 27: 339-344, 2002.

37. Verhoeven JE, Révész D, Epel ES, Lin J, Wolkowitz OM and Penninx BW: Major depressive disorder and accelerated cellular aging: Results from a large psychiatric cohort study. Mol Psychiatry 19: 895-901, 2014

38. Elvsåshagen T, Vera E, Bøen E, Bratlie J, Andreassen $\mathrm{OA}$, Josefsen D, Malt UF, Blasco MA and Boye B: The load of short telomeres is increased and associated with lifetime number of depressive episodes in bipolar II disorder. J Affect Disord 135 43-50, 2011.

39. Needham BL, Mezuk B, Bareis N, Lin J, Blackburn EH and Epel ES: Depression, anxiety and telomere length in young adults: Evidence from the National Health and Nutrition Examination Survey. Mol Psychiatry 20: 520-528, 2015.

40. Lung FW, Chen NC and Shu BC: Genetic pathway of major depressive disorder in shortening telomeric length. Psychiatr Genet 17: 195-199, 2007.

41. Phillips AC, Robertson T, Carroll D, Der G, Shiels PG McGlynn L and Benzeval M: Do symptoms of depression predict telomere length? Evidence from the west of Scotland twenty-07 study. Psychosom Med 75: 288-296, 2013.

42. Wikgren M, Maripuu M, Karlsson T, Nordfjäll K, Bergdahl J, Hultdin J, Del-Favero J, Roos G, Nilsson LG, Adolfsson R and Norrback KF: Short telomeres in depression and the genera population are associated with a hypocortisolemic state. Biol Psychiatry 71: 294-300, 2012.

43. Hartmann N, Boehner M, Groenen F and Kalb R: Telomere length of patients with major depression is shortened but independent from therapy and severity of the disease. Depress Anxiety 27 $1111-1116,2010$

44. Simon NM, Walton ZE, Bui E, Prescott J, Hoge E, Keshaviah A, Schwarz N, Dryman T, Ojserkis RA, Kovachy B, et al: Telomere length and telomerase in a well-characterized sample of individuals with major depressive disorder compared to controls. Psychoneuroendocrinology 58: 9-22, 2015.

45. Puterman E and Epel E: An intricate dance: Life experience, multisystem resiliency, and rate of telomere decline throughout the lifespan. Soc Personal Psychol Compass 6 $807-825,2012$

46. Czepielewski LS, Massuda R, Panizzutti B, da Rosa ED, de Lucena D, Macêdo D, Grun LK, Barbé-Tuana FM and Gama CS Telomere length in subjects with schizophrenia, their unaffected siblings and healthy controls: Evidence of accelerated aging. Schizophr Res 174: 39-42, 2016.

47. Shastry BS: Schizophrenia: A genetic perspective (Review). Int J Mol Med 9: 207-212, 2002

48. Rao S, Ye N, Hu H, Shen Y and Xu Q: Variants in TERT influencing telomere length are associated with paranoid schizophrenia risk. Am J Med Genet B Neuropsychiatr Genet 171B: 317-324, 2016

49. Yu WY, Chang HW, Lin CH and Cho CL: Short telomeres in patients with chronic schizophrenia who show a poor response to treatment. J Psychiatry Neurosci 33: 244-247, 2008.

50. Wolkowitz OM, Jeste DV, Martin AS, Lin J, Daly RE, Reuter C and Kraemer H: Leukocyte telomere length: Effects of schizophrenia, age, and gender. J Psychiatr Res 85: 42-48, 2017.

51. Leykin I, Mayer R and Shinitzky M: Short and long-term immunosuppressive effects of clozapine and haloperidol Immunopharmacology 37: 75-86, 1997.

52. Müller N, Myint AM and Schwarz MJ: Inflammation in schizophrenia. Adv Protein Chem Struct Biol 88: 49-68, 2012.

53. Porton B, Delisi LE, Bertisch HC, Ji F, Gordon D, Li P, Benedict MM, Greenberg WM and Kao HT: Telomerase levels in schizophrenia: A preliminary study. Schizophr Res 106: 242-247, 2008

54. Rao S, Kota LN, Li Z, Yao Y, Tang J, Mao C, Jain S, Xu Y and $\mathrm{Xu}$ Q: Accelerated leukocyte telomere erosion in schizophrenia: Evidence from the present study and a meta-analysis. J Psychiatr Res 79: 50-56, 2016.

55. Savolainen K, Räikkönen K, Kananen L, Kajantie E, Hovatta I, Lahti M, Lahti J, Pesonen AK, Heinonen K and Eriksson JG: History of mental disorders and leukocyte telomere length in late adulthood: The Helsinki Birth Cohort Study (HBCS). J Psychiatr Res 46: 1346-1353, 2012

56. Beaulieu JM and Gainetdinov RR: The physiology, signaling, and pharmacology of dopamine receptors. Pharmacol Rev 63: 182-217, 2011.
57. Hoffmeyer K, Raggioli A, Rudloff S, Anton R, Hierholzer A, Del Valle I, Hein K, Vogt R and Kemler R: Wnt/ $\beta$-catenin signaling regulates telomerase in stem cells and cancer cells. Science 336: 1549-1554, 2012.

58. Schizophrenia Working Group of the Psychiatric Genomics Consortium. Biological insights from 108 schizophrenia-associated genetic loci. Nature 511: 421-427, 2014

59. Okusaga OO: Accelerated aging in schizophrenia patients: The potential role of oxidative stress. Aging Dis 5: 256-262, 2013.

60. Okusaga O, Hamilton RG, Can A, Igbide A, Giegling I, Hartmann AM, Konte B, Friedl M, Reeves GM, Rujescu D and Postolache TT: Phadiatop seropositivity in schizophrenia patients and controls: A preliminary study. AIMS Public Health 1: 43-50, 2014.

61. Kirkpatrick B and Galderisi S: Deficit schizophrenia: An update. World Psychiatry 7: 143-147, 2008.

62. Kao HT, Cawthon RM, Delisi LE, Bertisch HC, Ji F, Gordon D, Li P, Benedict MM, Greenberg WM and Porton B: Rapid telomere erosion in schizophrenia. Mol Psychiatry 13: 118-119, 2008.

63. Polho GB, De-Paula VJ, Cardillo G, dos Santos B and Kerr DS: Leukocyte telomere length in patients with schizophrenia: A meta-analysis. Schizophr Res 165: 195-200, 2015.

64. Prabakaran S, Swatton JE, Ryan MM, Huffaker SJ, Huang JT, Griffin JL, Wayland M, Freeman T, Dudbridge F, Lilley KS, et al: Mitochondrial dysfunction in schizophrenia: Evidence for compromised brain metabolism and oxidative stress. Mol Psychiatry 9: 684-697, 2004.

65. Nishioka $\mathrm{N}$ and Arnold SE: Evidence for oxidative DNA damage in the hippocampus of elderly patients with chronic schizophrenia. Am J Geriatr Psychiatry 12: 167-175, 2004.

66. Yao JK, Reddy R, McElhinny LG and van Kammen DP: Reduced status of plasma total antioxidant capacity in schizophrenia. Schizophr Res 32: 1-8, 1998.

67. Khan MM, Evans DR, Gunna V, Scheffer RE, Parikh VV and Mahadik SP: Reduced erythrocyte membrane essential fatty acids and increased lipid peroxides in schizophrenia at the nevermedicated first-episode of psychosis and after years of treatment with antipsychotics. Schizophr Res 58: 1-10, 2002

68. Ranjekar PK, Hinge A, Hegde MV, Ghate M, Kale A, Sitasawad S, Wagh UV, Debsikdar VB and Mahadik SP: Decreased antioxidant enzymes and membrane essential polyunsaturated fatty acids in schizophrenic and bipolar mood disorder patients. Psychiatry Res 121: 109-122, 2003.

69. Epel ES: Psychological and metabolic stress: A recipe for accelerated cellular aging? Hormones (Athens) 8: 7-22, 2009.

70. Grahame TJ and Schlesinger RB: Oxidative stress-induced telomeric erosion as a mechanism underlying airborne particulate matter-related cardiovascular disease. Part Fibre Toxicol 9: 21, 2012.

71. von Zglinicki T, Bürkle A and Kirkwood TB: Stress, DNA damage and ageing - an integrative approach. Exp Gerontol 36: 1049-1062, 2001

72. Huzen J, Wong LS, van Veldhuisen DJ, Samani NJ, Zwinderman AH, Codd V, Cawthon RM, Benus GF, van der Horst IC, Navis G, et al: Telomere length loss due to smoking and metabolic traits. J Intern Med 275: 155-163, 2014.

73. Broer L, Codd V, Nyholt DR, Deelen J, Mangino M, Willemsen G, Albrecht E, Amin N, Beekman M, de Geus EJ, et al: Meta-analysis of telomere length in 19,713 subjects reveals high heritability, stronger maternal inheritance and a paternal age effect. Eur J Hum Genet 21: 1163-1168, 2013

74. Lindqvist D, Epel ES, Mellon SH, Penninx BW, Révész D, Verhoeven JE, Reus VI, Lin J, Mahan L, Hough CM, et al: Psychiatric disorders and leukocyte telomere length: Underlying mechanisms linking mental illness with cellular aging. Neurosci Biobehav Rev 55: 333-364, 2015.

75. Verhoeven JE, van Oppen P, Puterman E, Elzinga B and Penninx BW: The association of early and recent psychosocial life stress with leukocyte telomere length. Psychosom Med 77: 882-891, 2015.

76. Hoen PW, Rosmalen JG, Schoevers RA, Huzen J, van der Harst P and de Jonge P: Association between anxiety but not depressive disorders and leukocyte telomere length after 2 years of follow-up in a population-based sample. Psychol Med 43: 689-697, 2013.

77. Malouff JM and Schutte NS: A meta-analysis of the relationship between anxiety and telomere length. Anxiety Stress Coping 30: 264-272, 2017

78. Mathur MB, Epel E, Kind S, Desai M, Parks CG, Sandler DP and Khazeni N: Perceived stress and telomere length: A systematic review, meta-analysis, and methodologic considerations for advancing the field. Brain Behav Immun 54: 158-169, 2016. 
79. Wang X, Sundquist K, Hedelius A, Palmér K, Memon AA and Sundquist J: Leukocyte telomere length and depression, anxiety and stress and adjustment disorders in primary health care patients. BMC Psychiatry 17: 148, 2017.

80. Weischer M, Bojesen SE, Cawthon RM, Freiberg JJ, Tybjærg-Hansen A and Nordestgaard BG: Short telomere length, myocardial infarction, ischemic heart disease, and early death. Arterioscler Thromb Vasc Biol 32: 822-829, 2012.

81. Wentzensen IM, Mirabello L, Pfeiffer RM and Savage SA: The association of telomere length and cancer: A meta-analysis. Cancer Epidemiol Biomarkers Prev 20: 1238-1250, 2011.
82. Willeit P, Raschenberger J, Heydon EE, Tsimikas S, Haun M, Mayr A, Weger S, Witztum JL, Butterworth AS, Willeit J, et al: Leucocyte telomere length and risk of type 2 diabetes mellitus: New prospective cohort study and literature-based meta-analysis. PLoS One 9: e112483, 2014.

This work is licensed under a Creative Commons Attribution-NonCommercial-NoDerivatives 4.0 International (CC BY-NC-ND 4.0) License. 